\title{
BC contracting-out a threat to privacy and health acts
}

The BC government is facing a court challenge over its decision to hire a US firm to help manage its medical and pharmaceutical plans. The contract with Maximus Inc., to be finalized in late summer, could ultimately give the US government access to $\mathrm{BC}$ residents' health care information and open the doors to privatization from US companies, critics charge.

The BC Ministry of Health Services says the contract is "aimed at providing greater efficiency and better value for taxpayers." Suzanne Germain said: "The advantage for us is to provide specialized expertise and technology. The technology the Medical Services Plan uses is paper-based and outmoded."

Maximus would enroll applicants in medicare, register family changes, receive applications from people unable to pay BC's premiums and pay health professionals.

Opponents say the contract will give American authorities access to individuals' health records, including patients with AIDS and those using medical marijuana. This is because the US Patriot Act allows the FBI to obtain databases from American corporations. It also prohibits corporations from revealing to clients that their information has been passed on to the FBI.

Even if the information is physically in Canada and held by a Canadian subsidiary the American parent could be required to disclose it, states the BC Government Employees Union, which recently filed a court challenge on the grounds the contract violates the Canada
Health Act. In June, a coalition of privacy and health advocates launched another campaign against the contract.

Others are concerned that contracting out medicare administration in BC may open the door to privatization across the country. This type of contracting out may violate the public administration requirement of the Canada Health Act, says Ontario trade and public health care lawyer Steven Shrybman.

It may also set a precedent under the North American Free Trade Agreement (NAFTA). "There are lots of Canadian policies and laws that contradict [NAFTA] and we're allowed to keep them [only] as long as we maintain them... . Once you liberalize you can't backtrack." Deborab fones, Vancouver

\section{Baseline Study}

\section{Canadian inmates unhealthy and high risk}

Men and women in Canadian jails are unhealthier - often significantly so - than the general population, according to the first-ever study of their health.

The baseline data provided in Health Care Needs Assessment of Federal Inmates Report (Canadian Journal of Public Health Suppl 1, March/April 2004) will be used by Correctional Service Canada to improve services and interventions.

The study finds that Canadian inmates fall short on most health measures:

- $1.8 \%$ of inmates are HIVpositive (compared with $0.13 \%$ of the general population);

- $4.7 \%$ of women, $1.7 \%$ of men are HIV-positive;

- $46 \%$ of men, $49 \%$ of women abuse alcohol;

- $51 \%$ of men and $67.5 \%$ of women abuse drugs;

- $23.6 \%$ have hepatitis C (compared with $0.8 \%$ of the general population);
- $31 \%$ of women, $15 \%$ of men report emotional or mental health problems.

The report will be useful in helping to improve service delivery and identifying appropriate interventions, says Lucie McClung, commissioner of Correctional Service Canada.

Delivery of health services in Canada's prisons has traditionally been centred on individual patients. A move to a population health focus is required, says the study's author Dr. Brent Moloughney, a Toronto-based specialist in public health and epidemiology.

He recommends instituting an effective surveillance system for infectious and chronic diseases, developing a comprehensive strategy for detecting and managing mental health problems and implementing a health information system.

"It is unclear who speaks for the health needs of inmates and places them on the agenda

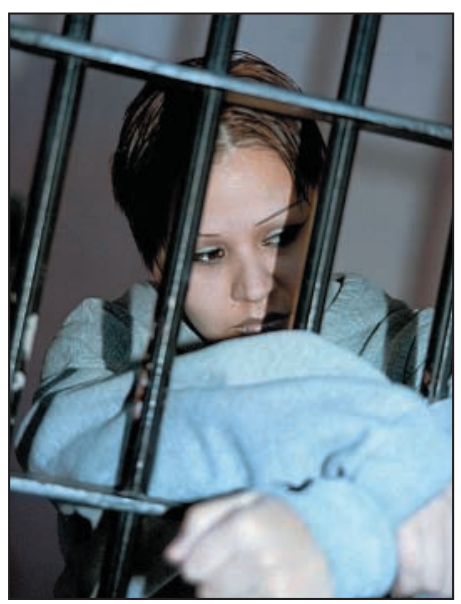

Who speaks for the health needs of inmates?

of decision-makers," said Moloughney.

"This is of particular importance for inmates since, as a group, they tend not to generate much public sympathy, nor are health services the primary mandate of [Correctional Service Canada]." - Donalee Moulton, Halifax 